\title{
COX-2 Expression Does Not Correlate with Microvessel Density in Breast Cancer
}

\author{
Mangesh A. Thorat Sanjana Mehrotra Akira Morimiya Sunil Badve \\ Department of Pathology and Laboratory Medicine, Indiana University School of Medicine, Indianapolis, Ind., USA
}

\author{
Key Words \\ Breast cancer - Cyclooxygenase - Angiogenesis • \\ Microvessel density $\cdot$ Immunohistochemistry
}

\begin{abstract}
Background: Cyclooxygenase-2 (COX-2), implicated in carcinogenesis and tumour progression in many cancers including breast cancer, is hypothesised to cause progression by promoting angiogenesis. The exact mechanism of such action is not known and the clinical evidence of such interaction is weak. We studied COX-2 expression and microvessel density (MVD) in malignant breast tissues. Methods: COX-2 expression was analysed by immunohistochemistry in 89 breast cancer cases. MVD was assessed by CD31 immunohistochemistry using the Chalkey count method. COX-2 expression and MVD data were correlated with each other and with other prognostic factors. Results: COX-2 expression, observed in $70(79 \%)$ cases, correlated positively with tumour type $(p=0.037)$ and tumour grade $(p=0.045)$, but negatively with oestrogen receptor $(p=0.013)$. It did not correlate with tumour size, axillary lymph node status, progesterone receptor and HER-2 status. MVD varied from 2.09 to 40.38 , correlated positively with tumour grade $(p=0.050)$ and tumour size $(p=0.044)$, but negatively with progesterone receptor $(p=0.040)$. MVD did not correlate with tumour type, axillary lymph node status, oestrogen receptor and HER-2. There was no correlation between COX-2 expression and MVD ( $p=0.702)$. Conclusions: COX-2 expression does not correlate with angiogenesis in breast cancer. Angiogenesis in breast cancer may be dependent on multiple genes, rather than on COX-2 alone.

Copyright $\odot 2009$ S. Karger AG, Basel
\end{abstract}

\section{Introduction}

Non-steroidal anti-inflammatory drugs (NSAIDs) are some of the most extensively studied chemopreventive agents for cancer. NSAIDs act through inhibition of cyclooxygenase (COX) enzyme. Epidemiological studies show lower incidence of colorectal cancer with NSAID use and randomised trials for prevention of colorectal adenoma confirm this observation $[1,2]$. However, similar studies investigating the relationship between NSAID use and breast cancer have reported conflicting results; some showed a significant reduction of $30-40 \%$ in breast cancer incidence associated with NSAID use [3-5], whereas others failed to confirm this relationship $[6,7]$.

The COX enzyme has 2 isoforms, COX-1 and COX-2, which are constitutive and inducible forms of the enzyme, respectively, and are coded by different genes $[8,9]$. Several studies have reported COX-2 over-expression in solid cancers including breast cancer [10], suggesting a possible role for COX-2 in carcinogenesis. Prevention of mammary tumour development in rat models by using selective COX-2 inhibitors [11] and forced COX-2 overexpression inducing tumorigenesis in transgenic mice [12] confirms such a role. COX-2 may also be involved in cancer progression as indicated by worse prognosis in COX-2-expressing tumours [13]. The suggested mechanisms for the role of COX-2 in breast cancer progression include promotion of angiogenesis [10] and induction of stromal aromatase enzyme [14].

M.A.T. and S.M. contributed equally to this work.

\section{KARGER}

Fax +41613061234 E-Mail karger@karger.ch www.karger.com
(C) 2009 S. Karger AG, Basel

$1015-2008 / 09 / 0761-0039 \$ 26.00 / 0$

Accessible online at:

www.karger.com/pat
Sunil Badve

Department of Pathology and Laboratory Medicine

Indiana University School of Medicine, 635 Barnhill Drive, MS-A128

Indianapolis, IN 46202 (USA)

Tel. +1 317491 6417, Fax +1 317491 6419, E-Mail sbadve@iupui.edu 
A selective COX-2 inhibitor like celecoxib is shown to inhibit fibroblast growth factor (FGF)-induced corneal angiogenesis in rat models [10]. Prostaglandin E2, which is a direct product of COX-2 action, is shown to induce vascular endothelial growth factor (VEGF) and basic FGF [15]. Based on this evidence, it is plausible that COX2 induces angiogenesis in breast cancer. However, the exact mechanism of such a suggested role is not yet fully understood and clinical evidence for such an association is preliminary; only 2 studies $[16,17]$ to date have reported such a relationship.

In this study, we assessed the relationship between COX-2 expression, angiogenesis as assessed by microvessel density (MVD) estimation and conventional prognostic variables in breast cancer, like tumour type, grade, nodal status, hormone receptor status and HER-2 status.

\section{Patients and Methods}

\section{Patient Characteristics}

Following approval by the institutional review board at Indiana University, we randomly selected 89 breast cancer patients who had undergone curative surgery without any neoadjuvant treatment and examined representative sections from these cases. Patient and tumour characteristics are detailed in table 1 . In addition to the invasive components, these tissue specimens also contained foci of normal breast lobules, fibrocystic disease and carcinoma in situ.

\section{Immunohistochemical Staining for COX-2}

Following dewaxing and hydration, sections $(4 \mu \mathrm{m})$ from archival paraffin-embedded tissue were treated with a combination of $75 \%$ glycerol and $25 \% 1 \times$ Dako high $\mathrm{pH}$ antigen retrieval solution (Dako, Carpinteria, Calif., USA) [18] in a decloaking chamber (BioCare, Walnut Creek, Calif., USA) with chamber settings of SP $1125^{\circ} \mathrm{C}$ for $5 \mathrm{~min}$ and SP $290^{\circ} \mathrm{C}$ for $10 \mathrm{~s}$. The slides were then cooled for $20 \mathrm{~min}$ at room temperature. Endogenous peroxidase activity was blocked by Peroxo-block (Invitrogen, Carlsbad, Calif., USA) for $1 \mathrm{~min}$. The slides were then incubated with monoclonal mouse anti-human COX- 2 antibodies (1: 50, clone CX229; Cayman Chemical, Ann Arbor, Mich., USA) for $1 \mathrm{~h}$ at room temperature. The sections were incubated with horseradish peroxidase polymer conjugate (Invitrogen) according to the manufacturer's instructions. The stain was visualised using DAB plus (Dako) and haematoxylin QS (Vector Laboratories, Burlingame, Calif., USA) counterstain. Specificity of the staining was verified by using 360107 COX-2 (human) blocking peptide (Cayman Chemical).

\section{Immunohistochemical Staining for CD31}

Antigen retrieval was done in Dako target retrieval solution (Dako) for $20 \mathrm{~min}$ in a $95^{\circ} \mathrm{C}$ water bath. Endogenous peroxidase activity was blocked using $3 \%$ hydrogen peroxide (diluted in water). Endogenous biotin and avidin was blocked using Dako avi-
Table 1. Patient and tumour characteristics

\begin{tabular}{llc}
\hline & & $n(\%)$ \\
\hline Sex & female & $88(99)$ \\
& male & $1(1)$ \\
\hline Age & $<50$ years & $31(35)$ \\
& $\geq 50$ years & $58(65)$ \\
\hline Type of tumour & IDC & $78(88)$ \\
& ILC & $11(12)$ \\
\hline Histological grade & I & $18(20)$ \\
& II & $41(46)$ \\
& III & $30(34)$ \\
\hline Lymph node status & positive & $37(42)$ \\
& negative & $44(49)$ \\
& unknown & $8(9)$ \\
\hline ER status & positive & $53(60)$ \\
\hline PR status & negative & $36(40)$ \\
& positive & $35(39)$ \\
HER-2 status & negative & $54(61)$ \\
\hline & positive & $48(54)$ \\
& negative & $41(46)$
\end{tabular}

IDC = Invasive duct carcinoma ILC $=$ invasive lobular carcinoma.

din/biotin blocking system each for $10 \mathrm{~min}$; nonspecific binding was minimised using a protein block (Dako) for $20 \mathrm{~min}$. Slides were then incubated for $30 \mathrm{~min}$ with Dako mouse monoclonal CD31 (prediluted, clone JC70A) followed by sequential application of Dako-LSAB2 biotinylated link antibody and Dako-LSAB2 streptavidin labelled with horseradish peroxidase for $15 \mathrm{~min}$ each. 3,3'-Diaminobenzidine tetrahydrochloride was used as the chromogen for visualization; sections were counterstained with haematoxylin QS (Richard Allan Scientific, Kalamazoo, Mich., USA), dehydrated through ascending grades of alcohol, cleared in xylene, and mounted.

\section{Immunohistochemical Staining for Oestrogen Receptor,}

Progesterone Receptor and HER-2/neu

Immunohistochemical staining was performed on the serial sections. Oestrogen receptor (ER, clone SP1; NeoMarkers, Fremont, Calif., USA), progesterone receptor (PR, clone PR636; Dako) and Hercept Test ${ }^{\circledR}$ were performed using protocols recommended by the manufacturer.

\section{Evaluation of Immunohistochemical Staining}

ER and PR status were assessed from immunohistochemically stained sections using a $10 \%$ cut-off. HER-2/neu expression was scored as $0,1+, 2+$ and $3+$ as recommended by the manufacturer (Dako).

For COX-2, the percentage of tumour cells with granular cytoplasmic staining (fig. 1) was scored from 0 to $4(0=0 \%$ positive 


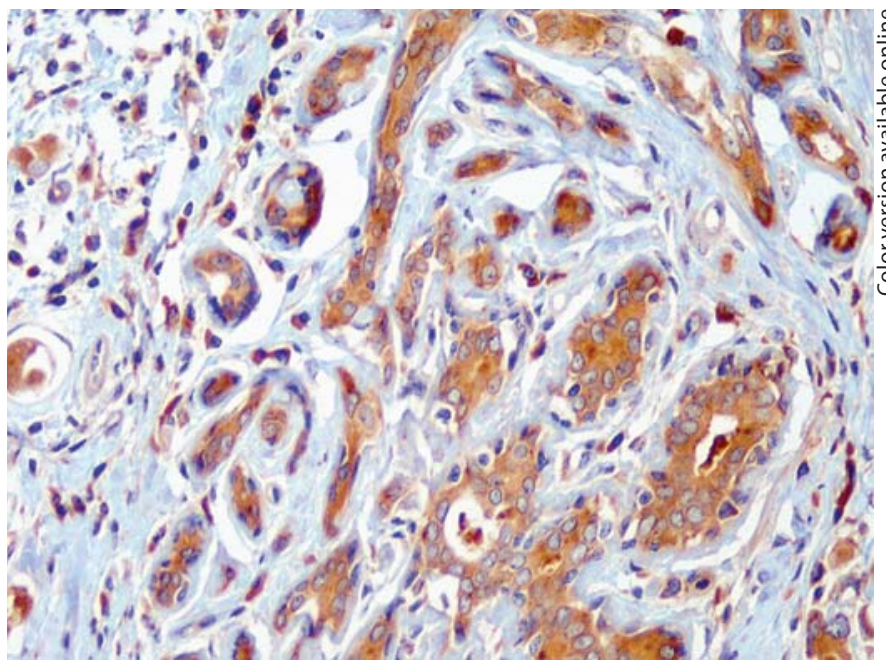

Fig. 1. COX-2 expression in breast cancer: tumour cells showing diffuse cytoplasmic staining.

cells; $1=<10 \%$ positive cells; $2=10-50 \%$ positive cells; $3=50$ $80 \%$ positive cells; $4=>80 \%$ positive cells) and staining intensity was scored from 0 to 3 ( 0 negative; 1 = weak; 2 = moderate; $3=$ strong). The 2 scores were then multiplied. Final scores of more than 6 were regarded as positive expression $[13,19]$. Expression of COX-2 in endothelial cells was also recorded and served as internal positive control.

MVD was counted using previously described methods [2022]. Briefly, the tumour was scanned at low power to identify the 3 areas of greatest vessel density. These areas were then examined under high power $\left(0.7386 \mathrm{~mm}^{2} / 200 \times\right.$ field $)$. Any brown staining endothelial cell or cell cluster clearly separated from adjacent microvessels was counted (fig. 2). A vessel lumen or the presence of red cells was not required; microvessels with a diameter $>50 \mu \mathrm{m}$ were excluded. Both the maximum and average of all 3 fields were reported.

\section{Statistical Analysis}

All analyses were performed using SPSS 14.0 software (SPSS Inc., Chicago, Ill., USA). Student's T, ANOVA, $\chi^{2}$ and Fisher's exact tests were applied for comparisons between 2 parameters. $\mathrm{p}<$ 0.05 were considered significant. Bi-variate and partial correlations with appropriate control variable were performed to determine Spearman's rho values. All p values were 2-tailed unless specified otherwise.

\section{Results}

\section{Patient Characteristics}

The majority of breast tumours (88\%) were infiltrating ductal carcinomas, the rest being infiltrating lobular carcinomas (table 1). Median age at diagnosis was 54 years (range 28-85), and 31 (35\%) patients were less than 50

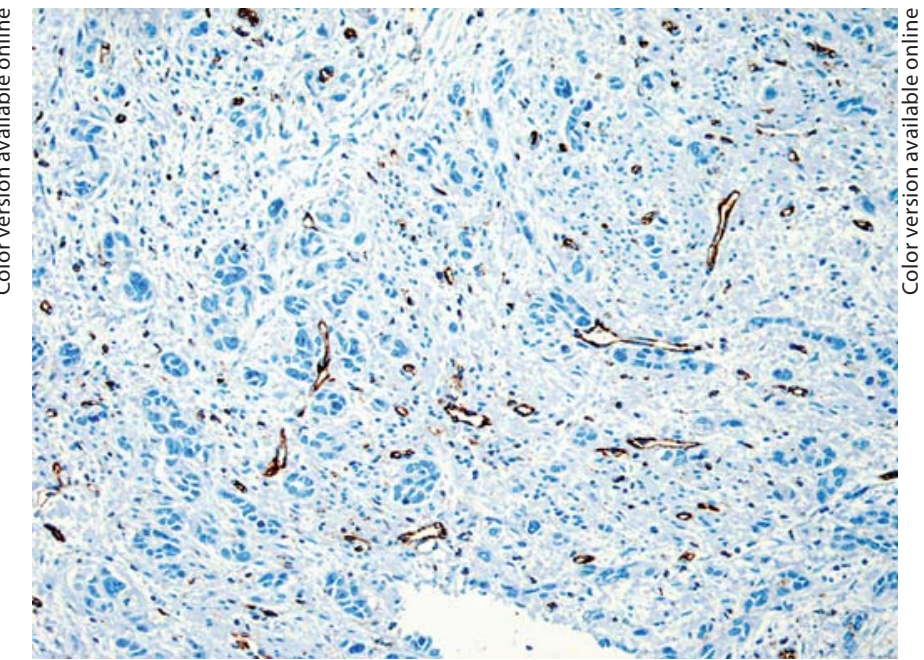

Fig. 2. Breast tumour showing angiogenesis: microvessels with endothelial cells showing CD31 expression.

years old. Tumour size ranged from 0.2 to $13 \mathrm{~cm}$ (median size $1.5 \mathrm{~cm})$. In 37 cases (42\%), axillary lymph nodes showed metastases. Fifty-three (60\%) and 35 (39\%) tumours expressed ER and PR, respectively, while 62 (70\%) tumours expressed either of the hormone receptors. HER2/neu was expressed in 48 cases (54\%) possibly due to selection of larger tumours. None of the lobular carcinoma showed HER-2/neu positivity.

\section{COX-2 in Breast Cancer by Immunohistochemistry}

The expression of COX-2 in tumour cells was seen in the form of diffuse cytoplasmic staining in breast lobules. In addition, the expression was seen in inflammatory cells and fibroblasts (fig. 1). COX-2 expression in tumour cells was studied, it was present in 70 (79\%) cases and absent in 19 (21\%) cases. We also observed COX-2 expression in the intra-tumoral blood vessel endothelia.

Sixty-four of 78 (82\%) infiltrating duct carcinomas showed COX-2 expression compared to only 6 of 11 (55\%) infiltrating lobular carcinomas $(\mathrm{p}=0.037)$. COX-2 expression correlated positively with tumour grade, whereas it correlated negatively with ER (table 2). There was no correlation between COX-2 expression and tumour size, axillary lymph node status, PR and HER-2 status. Also, COX-2 expression did not correlate with $\operatorname{MVD}(\mathrm{p}=$ $0.702)$.

\section{Microvessel Density}

MVD varied from 2.09 to 40.38 in the tumours studied (mean 20.35). Although MVD did not differ signifi- 
cantly between different tumour types $(p=0.459)$, tumours with higher grades had higher MVD ( $\mathrm{p}=0.050)$. Axillary lymph node-positive tumours did not have higher MVD compared to node-negative tumours $(\mathrm{p}=0.564)$. ER-positive or HER-2-positive tumours did not have significantly different MVD compared to ER-negative ( $\mathrm{p}=$ $0.236)$ or HER-2-negative ( $\mathrm{p}=0.163)$ tumours, respectively. Tumours not expressing PR had higher MVD compared to those expressing PR $(p=0.040)$. Tumours smaller than $1 \mathrm{~cm}$ in size had lower MVD compared to tumours between 1 and $2 \mathrm{~cm}$ in size $(\mathrm{p}=0.044)$ or larger than $2 \mathrm{~cm}$ in size.

Since a high proportion of tumours in this series were HER-2 positive, it was essential to rule out any interference of HER-2 positivity in COX-2 and MVD relationship. Correlation analysis controlling for HER-2 did not change results with COX-2 showing absence of correlation with MVD ( $\mathrm{p}=0.473)$.

\section{Discussion}

\section{COX-2 Expression in Breast Cancer}

COX-2 expression in breast cancer and its relation with the prognosis have been previously reported $[13,23-$ 26]. The general consensus of these studies is that COX-2 expression is associated with poor prognosis in breast cancer. Ristimaki et al. [13] analysed COX-2 expression by immunohistochemistry in tissue array specimens of 1,576 invasive breast cancers. They observed that COX-2 expression was associated with large tumour size, high histological grade, axillary node metastases, ductal type of histology, negative hormone receptor status, high proliferation index, high p53 expression and presence of HER-2 expression.

We studied COX-2 expression and MVD by CD31 expression in 89 breast cancer specimens. We observed COX-2 expression in tumours, adjacent normal breast lobules, fibroblasts and inflammatory cells, a pattern similar to that described by Half et al. [27]. We observed that $79 \%$ of tumours expressed COX-2; these data are consistent with prior studies $[13,17,27]$. We also observed COX-2 expression in the endothelia of the vessels in the tumours expressing COX-2, a finding noted earlier by Davies et al. [17]. We observed that infiltrating duct carcinomas had significantly higher COX-2 expression than the lobular carcinomas and COX-2 expression correlated positively with tumour grade and negatively with ER, findings that are congruent with other large COX-2 expression studies in breast cancer.
Table 2. Bi-variate analysis of COX-2 with other disease markers

\begin{tabular}{lrrll}
\hline Parameter & $\begin{array}{c}\text { COX-2 } \\
\text { negative }\end{array}$ & $\begin{array}{l}\text { COX-2 } \\
\text { positive }\end{array}$ & $\begin{array}{l}\text { Correlation } \\
\text { coefficient }\end{array}$ & $\begin{array}{l}\text { Significance } \\
\text { (2-tailed) }\end{array}$ \\
\hline Histology type & & & & \\
$\quad$ IDC & $14(18)$ & $64(82)$ & -0.221 & 0.037 \\
$\quad$ ILC & $5(45)$ & $6(55)$ & & \\
Histology grade & & & & \\
$\quad$ I & $6(33)$ & $12(67)$ & 0.213 & 0.045 \\
$\quad$ II & $10(24)$ & $31(76)$ & & \\
III & $3(10)$ & $27(90)$ & & \\
Tumour size & & & & \\
$\quad<1$ cm & $7(24)$ & $22(76)$ & 0.109 & 0.309 \\
$\quad 1-2$ cm & $9(26)$ & $26(74)$ & & \\
$\quad>2$ cm & $3(12)$ & $22(88)$ & & \\
Nodal status & & & & \\
$\quad$ Negative & $10(23)$ & $34(77)$ & 0.021 & 0.842 \\
$\quad$ Positive & $7(19)$ & $30(81)$ & & \\
ER & & & & \\
$\quad$ Negative & $3(8)$ & $33(92)$ & -0.262 & 0.013 \\
$\quad$ Positive & $16(30)$ & $37(70)$ & & 0.424 \\
PR & & & & \\
$\quad$ Negative & $10(19)$ & $44(81)$ & -0.086 & 0.094 \\
$\quad$ Positive & $9(26)$ & $26(74)$ & & \\
HER-2 & & & & \\
$\quad$ Negative & $12(29)$ & $29(71)$ & 0.179 & 0.041 \\
$\quad$ Positive & $7(15)$ & $41(85)$ & & 0.702 \\
MVD & & & & \\
\hline
\end{tabular}

Figures in parentheses are percentages. IDC = Invasive duct carcinoma; ILC = invasive lobular carcinoma.

\section{MVD in Breast Cancer}

A meta-analysis [28] of 43 independent studies, together involving 8,936 patients, has shown that high MVD significantly predicts poorer survival. This metaanalysis did not analyse correlation of MVD with other established prognostic factors in breast cancer. However, some of the studies included in this meta-analysis did analyse such a relationship between MVD and other prognostic factors in breast cancer. Although the findings of individual studies vary, probably due to use of different methods, results from larger studies generally show that MVD in breast cancer correlates with tumour grade and tumour size $[29,30]$, while it does not correlate with ER [30-32], HER-2 [31, 32] or nodal status [30-32]. We also noted similar results in our study. We observed that MVD correlated positively with tumour grade and size. Similarly, we did not find any correlation between MVD and ER, HER-2 or nodal status. 


\section{COX-2 and MVD Correlation in Breast Cancer}

Two studies $[16,17]$ have specifically addressed the question of inter-relationship between COX-2 and angiogenesis. Costa et al. [16] studied COX-2 and angiogenesis by factor VIII immunohistochemistry in 46 breast cancer patients; 8 of these patients (17.4\%) expressed COX-2. Davies et al. [17] reported correlation between COX-2 and MVD by CD31 expression in their study of 86 patients. They observed COX-2 expression in 79\% patients and noted simultaneous expression in tumour cells and neovasculature. Both studies reported a positive correlation between COX-2 and angiogenesis.

Contrary to these studies [16, 17], we did not observe any such correlation between COX-2 and MVD. In a study by Costa et al. [16], a small subset of 8 tumours showed COX-2 expression, and the study by Davies et al. [17] did not observe any correlation between COX-2 expression and tumour histology or hormone receptor status. This finding is not concordant with the results of larger COX-2 expression studies, raising the possibility of selection bias.

At molecular level, too, the exact mechanism of the influence of COX-2 in angiogenesis is not fully understood. In vitro experiments using cell lines have shown that prostaglandin E2, a product of direct COX-2 action, induces VEGF and basic FGF [15]. It is hypothesised that COX-2 can modulate production of angiogenic factors [33], especially VEGF, by changing expression of many angiogenesis-related genes [34]. However, the most recent evidence [35] from a comprehensive cell line and animal model study shows that switching-off of 4 genes (COX-2, MMP1, MMP2 and EREG) is required for decreasing an- giogenesis in breast tumour animal models; inhibition of only 1 of these 4 genes was not sufficient. These authors also report that such 4 gene-mediated decrease in angiogenesis is independent of VEGF levels. Results from this comprehensive study suggest that angiogenesis may not be dependent on a single gene like COX-2 and probably is induced after a complex interaction between multiple genes, COX-2 being merely one of these genes.

The absence of correlation between COX-2 expression and angiogenesis in breast cancer seen in the present study should be viewed in the context of (1) lack of strong laboratory mechanistic evidence of such correlation, (2) the recently suggested 4-gene model of angiogenesis dependence, (3) clinical evidence of such correlation, which at best can be termed as weak evidence, and (4) concordance of our COX-2 expression results and MVD assessment results individually with existing body of evidence in the literature confirming external validity of our findings. Results of our clinical study suggest that angiogenesis in breast cancer may not be dependant on a single gene like COX-2 as suggested earlier. At the very least, it calls for a larger clinical study, simultaneously looking at expression of multiple genes, tumour angiogenesis and serum markers of angiogenesis to understand true in vivo relationships.

\section{Acknowledgements}

Supported by the NCI grant to ECOG (CA 37403) 'Supplement for correlative studies related to ER-negative breast cancer-prostaglandin E2 receptors in breast cancer' to S.B., who is the guarantor of the present work.

\section{References}

1 Bertagnolli MM, Eagle CJ, Zauber AG, Redston M, Solomon SD, Kim K, et al: Celecoxib for the prevention of sporadic colorectal adenomas. N Engl J Med 2006;355:873884.

-2 Thun MJ, Namboodiri MM, Heath CW Jr: Aspirin use and reduced risk of fatal colon cancer. N Engl J Med 1991;325:1593-1596.

-3 Nakatsugi S, Ohta T, Kawamori T, Mutoh M, Tanigawa T, Watanabe K, et al: Chemoprevention by nimesulide, a selective cyclooxygenase-2 inhibitor, of 2-amino-1-methyl6 - phenylimidazo[ 4,5 - b] py ridine (PhIP)-induced mammary gland carcinogenesis in rats. Jpn J Cancer Res 2000;91: 886-892.
4 Leris C, Mokbel K: The prevention of breast cancer: an overview. Curr Med Res Opin 2001;16:252-257.

5 Harris RE, Kasbari S, Farrar WB: Prospective study of nonsteroidal anti-inflammatory drugs and breast cancer. Oncol Rep 1999; 6:71-73.

-6 Egan KM, Stampfer MJ, Giovannucci E, Rosner BA, Colditz GA: Prospective study of regular aspirin use and the risk of breast cancer. J Natl Cancer Inst 1996;88:988-993.

7 Paganini-Hill A, Chao A, Ross RK, Henderson BE: Aspirin use and chronic diseases: a cohort study of the elderly. BMJ 1989;299: 1247-1250.
$>8$ Kujubu DA, Fletcher BS, Varnum BC, Lim RW, Herschman HR: TIS10, a phorbol ester tumor promoter-inducible mRNA from Swiss 3T3 cells, encodes a novel prostaglandin synthase/cyclooxygenase homologue. J Biol Chem 1991;266:12866-12872.

-9 Xie W, Chipman JG, Robertson DL, Erikson RL, Simmons DL: Expression of a mitogenresponsive gene encoding prostaglandin synthase is regulated by mRNA splicing. Proc Natl Acad Sci USA 1991;88:2692-2696.

10 Masferrer JL, Leahy KM, Koki AT, Zweifel BS, Settle SL, Woerner BM, et al: Antiangiogenic and antitumor activities of cyclooxygenase-2 inhibitors. Cancer Res 2000;60: 1306-1311. 
-11 Harris RE, Alshafie GA, Abou-Issa H, Seibert K: Chemoprevention of breast cancer in rats by celecoxib, a cyclooxygenase 2 inhibitor. Cancer Res 2000;60:2101-2103.

$\checkmark 12$ Liu CH, Chang SH, Narko K, Trifan OC, Wu MT, Smith E, et al: Overexpression of cyclooxygenase-2 is sufficient to induce tumorigenesis in transgenic mice. J Biol Chem 2001; 276:18563-18569.

13 Ristimaki A, Sivula A, Lundin J, Lundin M, Salminen T, Haglund C, et al: Prognostic significance of elevated cyclooxygenase- 2 expression in breast cancer. Cancer Res 2002; 62:632-635.

-14 Zhao Y, Agarwal VR, Mendelson CR, Simpson ER: Estrogen biosynthesis proximal to a breast tumor is stimulated by PGE2 via cyclic AMP, leading to activation of promoter II of the CYP19 (aromatase) gene. Endocrinology 1996;137:5739-5742.

- 15 Cheng T, Cao W, Wen R, Steinberg RH, LaVail MM: Prostaglandin E2 induces vascular endothelial growth factor and basic fibroblast growth factor mRNA expression in cultured rat Muller cells. Invest Ophthalmol Vis Sci 1998;39:581-591.

-16 Costa C, Soares R, Reis-Filho JS, Leitao D, Amendoeira I, Schmitt FC: Cyclo-oxygenase 2 expression is associated with angiogenesis and lymph node metastasis in human breast cancer. J Clin Pathol 2002;55:429-434.

-17 Davies G, Salter J, Hills M, Martin LA, Sacks $\mathrm{N}$, Dowsett M: Correlation between cyclooxygenase-2 expression and angiogenesis in human breast cancer. Clin Cancer Res 2003; 9:2651-2656.

-18 Beebe K: Glycerin antigen retrieval. Microsc Today 1999;30:30-31.

-19 Denkert C, Winzer KJ, Muller BM, Weichert W, Pest S, Kobel M, et al: Elevated expression of cyclooxygenase-2 is a negative prognostic factor for disease free survival and overall survival in patients with breast carcinoma. Cancer 2003;97:2978-2987.
20 Tynninen O, Sjostrom J, von Boguslawski K, Bengtsson NO, Heikkila R, Malmstrom P, et al: Tumour microvessel density as predictor of chemotherapy response in breast cancer patients. Br J Cancer 2002;86:1905-1908.

21 Weidner N, Folkman J, Pozza F, Bevilacqua $\mathrm{P}$, Allred EN, Moore DH, et al: Tumor angiogenesis: a new significant and independent prognostic indicator in early-stage breast carcinoma. J Natl Cancer Inst 1992;84:18751887.

22 Rubio L, Burgos JS, Morera C, Vera-Sempere FJ: Morphometric study of tumor angiogenesis as a new prognostic factor in nasopharyngeal carcinoma patients. Pathol Oncol Res 2000;6:210-216.

23 Chow LWC, Loo WTY, Wai CCY, Lui ELH, Zhu L, Toi M: Study of COX-2, Ki67, and p53 expression to predict effectiveness of 5-fluorouracil, epirubicin and cyclophosphamide with celecoxib treatment in breast cancer patients. Biomed Pharmacother 2005;59(suppl 2):S298-S301.

24 Kelly LM, Hill ADK, Kennedy S, Connolly EM, Ramanath R, Teh S, et al: Lack of prognostic effect of Cox-2 expression in primary breast cancer on short-term follow-up. Eur J Surg Oncol 2003;29:707-710.

25 Park K, Han S, Shin E, Kim HJ, Kim JY: Cox2 expression on tissue microarray of breast cancer. Eur J Surg Oncol 2006;32:10931096.

26 Zerkowski M, Camp R, Burtness B, Rimm D, Chung G: Quantitative analysis of breast cancer tissue microarrays shows high cox-2 expression is associated with poor outcome. Cancer Invest 2007;25:19-26.

27 Half E, Tang XM, Gwyn K, Sahin A, Wathen K, Sinicrope FA: Cyclooxygenase-2 expression in human breast cancers and adjacent ductal carcinoma in situ. Cancer Res 2002; 62:1676-1681.
28 Uzzan B, Nicolas P, Cucherat M, Perret GY: Microvessel density as a prognostic factor in women with breast cancer: a systematic review of the literature and meta-analysis. Cancer Res 2004;64:2941-2955.

29 Hansen S, Grabau DA, Sorensen FB, Bak M, Vach W, Rose C: The prognostic value of angiogenesis by Chalkley counting in a confirmatory study design on 836 breast cancer patients. Clin Cancer Res 2000;6:139-146.

-30 Vincent-Salomon A, Carton M, Zafrani B, Fréneaux P, Nicolas A, Massemin B, et al: Long term outcome of small size invasive breast carcinomas independent from angiogenesis in a series of 685 cases. Cancer 2001; 92:249-256.

31 Mayers MM, Seshadri R, Raymond W, McCaul K, Horsfall DJ: Tumor microvascularity has no independent prognostic significance for breast cancer. Pathology 1998;30:105110 .

32 Guidi AJ, Berry DA, Broadwater G, Helmchen B, Bleiweiss IJ, Budman DR, et al: Association of angiogenesis and disease outcome in node-positive breast cancer patients treated with adjuvant cyclophosphamide, doxorubicin, and fluorouracil: a Cancer and Leukemia Group B correlative science study from protocols 8541/8869. J Clin Oncol 2002;20:732-742.

>33 Tsujii M, Kawano S, Tsuji S, Sawaoka H, Hori M, DuBois RN: Cyclooxygenase regulates angiogenesis induced by colon cancer cells. Cell 1998;93:705-716.

34 Basu G, Liang W, Stephan D, Wegener L, Conley C, Pockaj B, et al: A novel role for cyclooxygenase- 2 in regulating vascular channel formation by human breast cancer cells. Breast Cancer Res 2006;8:R69.

35 Gupta GP, Nguyen DX, Chiang AC, Bos PD, Kim JY, Nadal C, et al: Mediators of vascular remodelling co-opted for sequential steps in lung metastasis. Nature 2007;446:765-770. 